\title{
Strategi Digital Marketing dalam Perdagangan Hasil Tani untuk Meningkatkan Pendapatan Kabupaten Karawang
}

\author{
Indah Krisnawati ${ }^{1)}$, Ibnu Auf Ubaidi ${ }^{2}$, Hanif Rais ${ }^{3)}$, Reminta Lumban Batu ${ }^{4)}$ \\ ${ }^{122334)}$ Program Studi Manajemen, Universitas Singaperbangsa Karawang \\ Jl. HS. Ronggo Waluyo, Puseurjaya, Kec. Telukjambe Tim., Kabupaten Karawang Jawa Barat 41361 \\ Email : indah.krisnawati16189@student.unsika.ac.id ${ }^{1}$, ibnu.auf16180@student.unsika.ac.id ${ }^{2}$, \\ hanif.rais18168@ student.unsika.ac.id ${ }^{3}$, reminta.lumban@fe.unsika.ac.id $^{4}$
}

\begin{abstract}
Karawang Regency is known as a national rice granary city where many people earn a living in the agricultural sector. Agriculture is one of the drivers of the national economy. The economic progress of a region can be seen from the aggregate economic growth which can be calculated through the Gross Regional Domestic Product (GRDP) which is weighted on average from the level of sectoral growth. Gross Regional Domestic Product (GRDP) is one of the measurement tools used to describe the level of development success. One of the outputs from the agricultural sector that is the mainstay of Karawang Regency's food crops is rice (rice), rice production and productivity in Karawang regency which functions fluctuatively and continues to increase every year, thus making farmers have to have a strategy in marketing more modern and efficient result. Digital Marketing is a marketing method that makes it easy for farmers to monitor and provide all the needs and desires of prospective consumers, prospective consumers can also find and get product information only by exploring the virtual world so as to facilitate the search process. The purpose of this research is to learn more about digital marketing strategies in trade in agricultural products to increase regional income Karawang Regency. This research data analysis technique uses descriptive analysis and verification. Determination of taking the number of respondents (samples) is done through the cluster sampling method. Testing this study uses PLS (Partial Least square). The results show that the digital marketing variable has a positive role of $42.8 \%$ of income and the negative competitiveness variable of $45.9 \%$ of income.
\end{abstract}

Keywords : Digital Marketing, Competitiveness, Income

\begin{abstract}
ABSTRAK
Kabupaten Karawang dikenal sebagai kota lumbung padi nasional dimana banyak masyarakat bermata pencaharian disektor pertanian. Pertanian merupakan salah satu roda penggerak perekonomian nasional. Kemajuan perekonomian suatu daerah dapat dilihat dari pertumbuhan ekonomi secara agregat yang dapat dihitung melalui Produk Domestik Regional Bruto (PDRB) yang rata-rata tertimbang dari tingkat pertumbuhan sektoralnya. Produk Domestik Regional Bruto (PDRB) merupakan salah satu alat ukur yang digunakan untuk menggambarkan tingkat keberhasilan pembangunan. Salah satu output dari sektor pertanian yang menjadi andalan dari tanaman pangan Kabupaten Karawang adalah beras (padi), Produksi dan produktivitas padi di kabupaten Karawang yang berfungsi fluktuatif dan terus meningkat setiap tahun, sehingga membuat petani harus memiliki strategi dalam memasarkan hasil yang lebih modern dan efesien. Digital Marketing merupakan suatu cara pemasaran yang memudahakan para petani memantau dan menyediakan segala kebutuhan dan keinginan calon konsumen, calon konsumen juga bisa mencari dan mendapatkan informasi produk hanya dengan cara menjelajah dunia maya sehingga mempermudah proses pencariannya Tujuan Penelitian ini untuk mempelajari lebih lanjut strategi pemasaran digital dalam perdagangan hasil tani untuk meningkatkan pendapatan daerah Kabupaten Karawang. Teknik analisis data penelitian ini menggunakan analisis deskripstif dan verifikatif. Penentuan pengambilan jumlah responden (sampel) dilakukan melalui metode cluster sampling. Pengujian penelitian ini menggunakan PLS (Partial Least square). Hasil menunjukkan bahwa variabel pemasaran digital berperan positif 42,8\% terhadap pendapatan dan sedangkan variabel daya saing negatif $45,9 \%$ terhadap pendapatan.
\end{abstract}

Kata kunci : Digital Marketing, Daya Saing, Pendapatan 


\section{Pendahuluan}

Perkembangan ekonomi suatu negara tidak dapat dipisahkan dari aktifitas pembangunan ekonomi. Salah satunya adalah pembangunan ekonomi daerah. Pembangunan ekonomi daerah adalah suatu proses dimana pemerintah daerah dan masyarakatnya mengelola setiap sumberdaya yang ada dan membentuk suatu pola kemitraan antara pemerintah daerah dengan sektor swasta untuk menciptakan suatu lapangan kerja baru dan merangsang perkembangan kegiatan ekonomi (pertumbuhan ekonomi) dalam wilayah tersebut (Siwu, 2018). PDRB merupakan salah satu alat ukur yang digunakan untuk menggambarkan tingkat keberhasilan pembangunan. Kemajuan perekonomian suatu daerah dapat dilihat dari pertumbuhan ekonomi secara agregat yang dapat dihitung melalui Produk Domestik Regional Bruto (PDRB) yang rata-rata tertimbang dari tingkat pertumbuhan sektoralnya (OVILIA, 2018). Daerah yang sedang melaksanakan pembangunan ekonomi adalah Kabupaten Karawang Provinsi Jawa Barat. Kabupaten Karawang adalah kabupaten yang memiliki perkembangan yang bagus, baik dari segi pendapatan daerah, taraf ekonomi maupun pendidikan penduduk. Perekonomian Kabupaten Karawang tidak terlepas dari pengaruh perekonomian regional (www.karawangkab.go.id, 2019).

Tabel 1. PDRB Perkapita Kabupaten Karawang (Juta Rupiah)

\begin{tabular}{|l|c|c|c|c|c|}
\hline \multicolumn{1}{|c|}{ Uraian } & $\mathbf{2 0 1 3}$ & $\mathbf{2 0 1 4}$ & $\mathbf{2 0 1 5}$ & $\mathbf{2 0 1 6}$ & $\mathbf{2 0 1 7}$ \\
\hline $\begin{array}{l}\text { ADBH/ at } \\
\text { current price }\end{array}$ & 63.64 & 69.47 & 73.50 & 79.50 & 85.07 \\
\hline $\begin{array}{l}\text { ADHK at 2010 } \\
\text { Contstant Price }\end{array}$ & 54.06 & 56.33 & 58.26 & 61.32 & 64.27 \\
\hline $\begin{array}{l}\text { Pertumbuhan } \\
\text { PDRB perkapita } \\
\text { ADHK 2010 }\end{array}$ & 6.70 & 4.21 & 3.42 & 5.26 & 4.81 \\
\hline $\begin{array}{l}\text { Jumlah } \\
\text { Penduduk } \\
\text { (ribu orang) }\end{array}$ & $2,225,383$ & $2,250,120$ & $2,273,579$ & $2,295,778$ & $2,316,489$ \\
\hline $\begin{array}{l}\text { Pertumbuhan } \\
\text { Jumlah } \\
\text { Penduduk } \\
\text { (persen) }\end{array}$ & 1,18 & 1,11 & 1,04 & 0,98 & 0,90 \\
\hline
\end{tabular}

Sumber : Badan Pusat statistic Kab. Karawang, 2017

Secara umum perekonomian diseluruh kabupaten/kota di Provinsi Jawa Barat mengalami pertumbuhan yang positif di tahun 2017. Pertumbuhan ekonomi Kabupaten Karawang sangat fluktuatif, yakni tumbuh sebesar 4,81 persen dengan ADBH/at Current price 85.07 juta rupiah. Dimana, jika pertumbuhan PDRB per kapita meningkat maka bisa diasumsikan bahwa rata-rata pendapatan yang diterima oleh setiap penduduk di wilayah tersebut juga meningkat. Penduduk di Kabupaten Karawang bermata pencaharian utama sebagai petani. Karawang termasuk dalam penghasil padi terbesar di Jawa Barat pada tahun 2016. Pada sektor pertanian terdiri dari lima sub sektor yaitu sub sektor tanaman pangan, sub sektor perkebunan, sub sektor kehutanan, sub sektor peternakan, sub sektor perikanan.Tanaman pangan merupakan sub sektor yang paling penting diantara sub sektor lainnya karena mampu menghasilkan bahan pangan untuk kelangsungan hidup. Salah satu output dari sektor pertanian yang menjadi andalan dari tanaman pangan Kabupaten Karawang adalah beras (padi) (Barat, 2018).

Selama periode Tahun 2012-2016 produksi padi di Kabupaten Karawang memperlihatkan tren fluktuatif positif. Kenaikan produksi padi pada periode tersebut relatif bervariasi.

Tabel 2. Data Produksi Dan Produktivitas Padi (Sawah/Ladang) Mneurut Kabupaten/Kota (Ton) Tahun 2012-2016

\begin{tabular}{|c|l|c|c|c|c|}
\hline No & \multicolumn{1}{|c|}{ Jenis Komoditas } & $\mathbf{2 0 1 3}$ & $\mathbf{2 0 1 4}$ & $\mathbf{2 0 1 5}$ & $\mathbf{2 0 1 6}$ \\
\hline 1 & Padi Sawah & & & & \\
& Luas Panen (ha) & 195.929 & 195.285 & 190.725 & 193.403 \\
& Produksi (Ton GKP) & 1.481 .466 & 1.485 .298 & $1.524 .842,55$ & 1.458 .126 \\
\hline & Produktivitas (Kw/ Ha) & 75,61 & 76,05 & 79,9 & 75,39 \\
\hline 2 & Padi Ladang & & & & \\
& Luas Panen (ha) & 3.338 & 3.234 & 1.901 & 1.499 \\
& Produksi (Ton GKP) & 11.400 & 13.204 & $6.261,95$ & 6.196 \\
\hline & Produktivitas (Kw/ Ha) & 34,15 & 40,83 & 32,9 & 41,33 \\
\hline
\end{tabular}

Sumber : Dinas Pertanian Kehutanan Perkebunan dan Peternakan Kab Karawang

Berdasarkan Tabel 1.2, sektor yang menjadi basis bisa menjadi sektor yang di andalkan karena Kabupaten Karawang memiliki tren yang fluktuatif baik. Oleh karena itu, sektor pertanian akan menibulkan peningkatan dalam Produk Domestik Regional Bruto (PDRB).

PDRB pada dasarnya merupakan jumlah nilai tambah yang dihasilkan oleh seluruh unit usaha dalam suatu daerah tertentu atau merupakan jumlah nilai barang dan jasa akhir (neto) yang dihasilkan oleh seluruh unit ekonomi. Salah satu pendekatan dalam menghitung PDRB adalah menggunakan pendekatan produksi yang merupakan jumlah nilai tambah atas barang dan jasa yang dihasilkan oleh berbagai unit produksi yang bertujuan untuk meningkatkan pendapatan dan taraf hidup masyarakat (Hasibuan, 2013).

Tabel 3. Peningkatan Kesejahteraan Petani Tahun 2013-2016 (Asumsi Pedapatan Petani Padi Sawah/Ha/Musim)

\begin{tabular}{|c|c|c|c|c|c|}
\hline No & Uraian & $\mathbf{2 0 1 3}$ & $\mathbf{2 0 1 4}$ & $\mathbf{2 0 1 5}$ & $\mathbf{2 0 1 6}$ \\
\hline 1 & $\begin{array}{l}\text { Pendapatan } \\
\text { petani }\end{array}$ & 17.817 .130 & 18.532 .000 & 27.275 .000 & 32.525 .400 \\
\hline
\end{tabular}

Sumber : Dinas Pertanian Kehutanan Perkebunan Peternakan Kab. Karawang.

Berdasarkan Tabel 1.3 Pendapatan petani pada Tahun 2015 dan Tahun 2016 meningkat sebesar 19,24\%, seiring dengan kenaikan harga gabah kering panen di pasaran.

Kesejahteraan petani merupakan salah satu hal utama yang menjadi perhatian pemerintah dalam upaya peningkatan ketahanan pangan. Di tengah laju pembangunan yang berimplementasikan pada berkurangnya lahan pertanian, penggunaan teknologi pertanian seiring kemajuan teknologi/informasi dapat memaksimalkan hasil pertanian. Bisnis dan strategi pemasaranpun perlu diubah untuk memperoleh peluang- 
peluang serta menghindari ancaman (Manek, 2013). Meningkatnya globalisasi ekonomi di dunia membuka kesempatan pasar yang luas bagi para perusahaan. Hal ini tentu akan menimbulkan persaingan bagi para pelaku pasar agar dapat mencapai kinerja yang lebih baik. Informasi merupakan media penting yang berperan dalam pengambilan keputusan. Informasi yang cepat dan lengkap akan membantu para pemasar agar dapat memenangkan persaingan. Adanya kemajuan dalam jaringan telepon digital, interactive cable television, personal computers, jasa/pelayanan online, dan internet, membuat informasi semakin cepat dan mudah diperoleh (Paul, 1996:27).

Sejalan dengan berkembangnya internet, muncul pemahaman baru mengenai paradigma pemasaran berupa konsep pemasaran modern yang berorientasi pada pasar atau konsumen atau revolusi pemasaran berupa electronic marketplace (Arnott dan Bridgewater, 2002; Bakos, 1999; Chaffey et. al., 2000; Eid dan Trueman, 2002) (Lakutomo, 2014).

Purwana et al. (2017) menyatakan lebih lanjut bahwa digital marketing adalah kegiatan promosi dan pencarian pasar melalui media digital secara online dengan memanfaatkan berbagai sarana misalnya jejaring sosial. Digital marketing memudahkan petani memantau dan menyediakan segala kebutuhan dan keinginan calon konsumen, calon konsumen juga bisa mencari dan mendapatkan informasi produk hanya dengan cara menjelajah dunia maya sehingga mempermudah proses pencariannya (Aisyah, 2018). Konten digital digunakan dalam berbagai cara berbeda dalam pertukaran pemasaran, biasanya digunakan sebagai teknik pemasaran inbound untuk menarik pelanggan ke situs web, dan untuk berpotensi menciptakan dinamika komunitas merek yang terkait dengan situs web (Holliman \& Rowley, 2014). World Wide Web (www) atau biasa dikenal dengan istilah Website adalah Sistem pengaksesan informasi dalam Internet yang paling terkenal. Laudon and Laudon, (2007:133) menjelaskan bahwa website adalah perpustakaan online mengenal informasi pelanggan selain menjadi pasar di mana barang dan jasa dibeli. Website memiliki pengaruh luar biasa pada pembelian off line, lebih dari $80 \%$ pembeli mobil baru meneliti mobil impian mereka secara online dahulu, karena website memberikan dan menyediakan informasi yang meyakinkan mengenai ulasan produk dan informasi yang di butuhkan oleh calon konsumen (Susanto, Susilo, Administrasi, \& Malang, 2013).

Berdasarkan latar belakang, maka perumusan masalah penelitian ini yaitu seberapa besar strategi digital marketing dalam perdagangan hasil tani untuk meningkatkan pendapatan daerah kabupaten Karawang. Tujuan penelitian ini yaitu untuk mengetahui seberapa besar strategi digital marketing dalam perdagangan hasil tani untuk meningkatkan pendapatan daerah kabupaten Karawang.

Penelitian ini penting dilakukan karena dengan cara penerapan strategi digital marketing pada perdagangan hasil petani dapat meningkatkan pendapatan daerah kabupaten Karawang. Penelitian ini diharapkan dapat bermanfaat dan dapat memberikan sumbangan secara teoritis dan praktik. Secara Teoritis, hasil penelitian ini harapkan dapat menambah wawasan dan menjadi sebuah sumbangan dalam upaya pengembangan ilmu strategi pemasaran, khususnya tentang digital marketing yang kemudian dapat menjadi bahan untuk dikaji lebih lanjut yang berkaitan daya saing. Kegunaan Empiris: Bagi perusahaan, Penelitian ini diharapkan dapat memberikan masukkan pihak manajemen atau pengelola perusahaan agar dapat meningkatkan pelayanan yang sesuai dengan keinginan konsumen. Bagi masyarakat, penelitian ini diharapkan dapat memberikan informasi dan pertimbangan apabila memiliki ketertarikan terhadap bisnis berbasis teknologi informasi dan bagi penulis, penelitian ini diharapkan dapat memberikan pemahaman mengenai digital marketing.

Proses penyesuaian pemasaran dari non digital menjadi digital memang membutuhkan pengetahuan mengenai apa yang menjadi sasaran konsumen. Misalnya, sistem pelayanan yang baik akan meningkatkan ketertarikan konsumen untuk mengunjungi toko atau website sehingga mendorong konsumen untuk melakukan keputusan pembelian secara langsung.

\section{Pembahasan}

Digital marketing adalah elemen bauran promosi yang memungkinkan interaksi secara interaktif atau dua arah dari sebuah informasi dimana pengguna dapat berpartisipasi dan memodifikasi bentuk dan isi dari informasi yang mereka terima pada saat itu (Belch \& Belch, 2015: 22 dalam Ulil Azmi, 2016). Tujuan dari kegiatan digital marketing adalah untuk mempromosikan suatu merek, membangun preferensi, dan meningkatkan penjualan melalui berbagai teknik digital marketing (Saveria, 2016).

Menurut Aditya M Salya (2010: 4) dalam (Anshari \& Mahani, 2018) disebutkan beberapa dimensi yang dapat digunakan dalam internet/digital marketing atau pemasaran digital, antara lain:

1. Website, yaitu membuat website persahaan atau organisasi yang bertujuan untuk memberikan informasi penting dan menarik kepada konsumen. Website penghubung dunia digital secara keseluruhan dan mungkin bagian yang paling penting dalam keseluruhan strategi pemasaran digital, dimana kegiatan online akan terarah langsung ke calon konsumen.

2. Search Engine Marketing, yaitu pemanfaatan business directory untuk menjaring pengunjung dengan bekerjasama dengan search engine. Seperti: Google dan Yahoo. Search Engine Marketing salah satu bagian penting dari website atau proses pengaturan konten dari website agar mudah ditemukan oleh pengguna internet yang sedang mencari konten yang relevan dengan yang ada di website, dan juga menyajikan konten agar dapat dengan mudah ditemukan oleh mesin-mesin pencari. 
3. Web Banner, yaitu membuat kotak atau bendera iklan yang menarik didalam suatu website perusahaan atau organisasi.

4. Social Network, yaitu masuk ke dalam suatu forum sosial gratis (social media) yang membahas akan suatu topik-topik terkini. Seperti: Wordpress, Facebook dan Twitter. Social Network sebuah peluang pemasaran, namun saat ini belum ada seseorangpun yang bisa menawarkan sistem periklanan dengan sangat fokus ke kelompok masyarakat yang sangat kecil (niche) atas dasar informasi profil yang didapatkan dari situs-situs jejaring sosial.

5. E-mail marketing, surat elektronik (e-mail) masih menjadi alat yang penting untuk kegiatan pemasaran digital, yang dikirimkan dengan tujuan untuk menjaga hubungan antara konsumen yang sudah ada maupun calon konsumen yang bersedia menerima informasi lewat $e$-mail.

6. Affiliate marketing and strategic partnership, kegiatan bermitra dengan organisasi/ perusahaan lain dan website-website untuk mencapai keuntungan bersama dari sebuah kerjasama untuk mempromosikan produk atau layanan.

Penelitian ini menggunakan dimensi Digital Marketing menurut menurut Aditya M Salya (2010: 4) yaitu website, search engine marketing, web banner, social network dan affiliate marketing.

Menurut Michael Porter terdapat empat faktor utama yang menentukan keunggulan bersang industri (1995:5) mengatakan bahwa: competition is at the core of the success or failure of firms. Persaingan adalah inti dari kesuksesan atau kegagalan perusahaan. Terdapat dua sisi yang ditimbulkan oleh persaingan,yaitu sisi kesuksesan karena mendorong perusahaan-perusahaan untuk lebih dinamis dan bersaing mnghasilkan produk serta memberikan layanan terbaik bagi pasarnya, sehingga persaingan dianggapnya sebagai peluang yang memotivasi. Sedangkan sisi lainnya adalah kegagalan karena akan memperoleh perusahaan0perusahaan yang bersifat statis, takut akan persaingan dan tidak mampu menghasilkan produk-produk yang berkualitas, sehingga persaingan merupakan ancaman bagi perusahaannya (Rohmanudin, 2017).

Dimensi daya saing berdasarkan diamond of porter competitibeness (Porter, 1980; Wiyadi, 2009) dalam (Reminta Lumban Batu, 2013) adalah

1. Chance. kesempatan adalah kejadian yang berada di luar kendali perusahaan. Hal ini menjadi penting karena mereka menciptakan diskontinuitas dimana beerapa keuntungan posisi kompetitif dan beberapa kehilangan.

2. Factor Conditions. Kondisi faktor sumber daya manusia, sumber daya fisik, sumber daya pengetahuan, sumber data modal dan infrastruktur

3. Demand Conditions. Kondisi permintaan di pasar dalam negeri dapat membantu perusahaan menciptakan keunggulan kompetitif. Kondisi pasar seperti ini ditamdai dengan kemampuan untuk menjual produk yang berkualitas yang terkait dengan hubungan perusahaan dan pelanggan dalam area pemasaran.

4. Firm trategy, Structure and Rivalry. Strategi perusahaan, struktur dan persaingan merupakan penentu ketempat saing. Cara di mana perusahaan diciptakan, menetapkan tujuan dan dikelola penting untuk sukses. Pentingnya kehadiran persaingan sengit menciptakan tekanan untuk berinovasi dalam rangka meningkatkan daya saing.

5. Related and Supporting Industries. Hubungan dan dukungan industry dapat menghasilkan masukan yang penting untuk berinovasi dan internasionalisme.

6. Government. Pemerintah dapat mempengaruhi masing-masing di atas emoat fakyor penentu daya saing. Pemerintah dapat mempengaruhi kondisi pasokan faktor kunci produksi, kondsi perintaan di pasar dalam negeri dan persaingan antara perusahaan. Intervensi pemerintah dapat terjadi pada tingkat local, regional, tingkat nasional atau supranasional.

Dimensi yang digunakan dalam penelitian ini adalah chance, factor condition, firm strategy, structure and rivalry dan government.

Menurut Iman Santoso (2009;340) dalam (Wibowo, 2018) Pendapatan adalah penghasilan yang timbul dari aktivitas perusahaan yang bisa (normal activity) dan dikenal dengan sebutan yang berbeda, misalnya: penjualan (sales), penghasilan jasa (fees revenues), pendapatan bunga (interest revenue), pendapatan dividen (dividend revenue), pendapatam royalty (royalty revenue) dan pendapatan sewa (rent revenue).

Dimensi yang digunakan dalam penelitian ini yaitu pendapatan meningkatkan volume penjualan dan persentase laba.

Penelitian ini menggunakan metode kuantitatif, dimana peneliti harus netral dan tidak memihak sesuai dengan apapun yang ditemukan dilapangan (Liputan6.com, 2019). Jenis data yang digunakan dalam penelitian ini adalah data primer dan sekunder. Penelitian ini mengambil lokasi di Kabupaten Karawang. Populasi penelitian ini adalah rumah tangga usaha pertanian di Kabupaten Karawang yang terdiri dari 123.143 rumah tangga yang tersebar di 30 Kecamatan. Peneliti memiliki beberapa keterbatasan yang mengakibatkan tidak mungkin semua dapat diteliti karena beberapa faktor diantaranya keterbatasan dana, tenaga, waktu dan keterbatasan fasilitas lain. Maka peneliti dapat memakai sampel yang diambil dari populasi (Sora N, 2015). Syarat sampel untuk memenuhi perhitungan PLS adalah 30-100 responden (Reminta Lumban Batu, 2013). Penentuan pengambilan jumlah responden (sampel) dilakukan melalui metode cluster sampling.

Teknik pengumpulan data dalam penelitian ini adalah studi kepustakaan, observasi, penyebaran kuesioner dan dokumentasi. Pengujian penelitian ini menggunakan PLS (Partial Least square). Teknik analisis data penelitian ini menggunakan analisis deskripstif dan verifikatif. Analisis deskriptif dengan menggunakan kuisioner yang disebarkan kepada responden agar diperoleh deskripsi tentang variabel-variabel penelitian. Teknik data 
verifikatif yang digunakan ialah dengan SEM - PLS. Penelitian ini menggunakan bantuan program SmartPLS3 untuk menghubungkan antara variabel laten dengan variabel manifest. Penelitian ini terdapat 3 variabel dengan jumlah varabel manifest sebanyak 13.

Penelitian ini bertujuan untuk menguji pengaruh digital marketing terhadap pendapatan dan daya saing terhadap pendapatan. Berdasarkan metode estimasi diperoleh diagram jalur full model sebagai berikut.

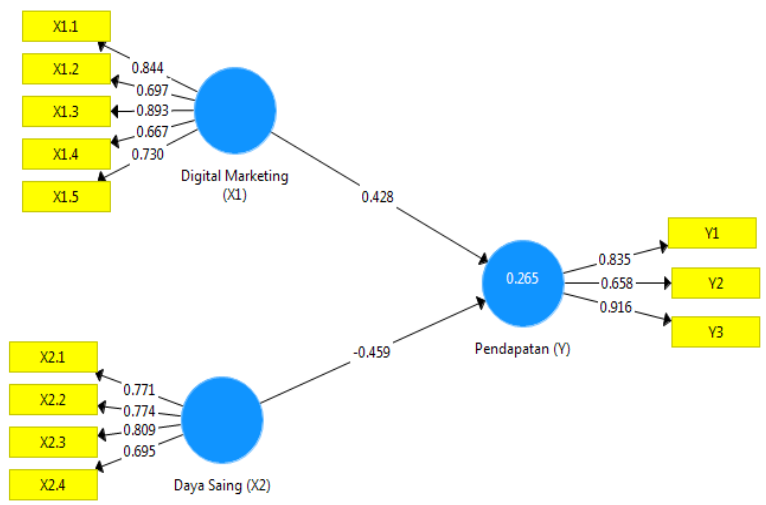

Gambar 1. Diagram Jalur Full Model

Berdasarkan Gambar 1 menunjukkan bahwa digital marketing berpengaruh positif $42,8 \%$ terhadap pendapatan dan daya saing berpengaruh negatif $45,9 \%$ terhadap pendapatan.

Penelitian ini mendukung penelitian sebelumnya yang mengemukakan bahwa yang mengemukakan bahwa digital marketing memudahkan pelaku UMKM untuk memberikan informasi dan berinteraksi secara langsung dengan konsumen, memperluas pangsa pasar, mengingkatkan awereness dan meningkatkan penjualan bagi pelaku UKM (Febriyantoro \& Arisandi, 2018) dan mendukung penelitian yang mnegemukakan bahwa digital marketing dipandang sebagai media yang paling baiksebagai sarana promosi yang paling efektif dan efesien serta mamp meningkatkan volume penjualan yang signifikan (Pradiani, 2017)

Penelitian ini mendukung penelitian yang menyatakan bahwa secara parsial variabel tenaga kerja tidak berpengaruh positif dan tidak signifikan terhadap pendapatan pengrajin kerajinan anyaman (Wulandari \& Darsana, 2017) dan mendukung penelitian yang mengemukakan bahwa variabel jumlah tenaga kerja memiliki pengaruh tetapi tidak signifikan terhadap pendapatan petani padi di Kecamatan Masaran.

\section{Kesimpulan}

Berdasarkan hasil penelitian yang telah dilakukan menggunakan analisis deskriptif dan verifikatif maka berdasarkan penelitian tersebut dapat diambil kesimpulan sebagai berikut:

1. Gambaran variabel digital marketing diukur melalui dimensi website, search engine marketing, web banner, social networking serta affiliate marketing. Rata-rata skor tertinggi terdapat pada dimensi Web
Banner. Hal ini menunjukkan adanya penilaian baik dari responden mengenai web Benner yang memberikan informasi dan promosi kepada konsumen. Sedangkan rata-rata skor terendah terdapat pada dimensi social networking.

2. Gambaran variabel daya saing diukur melalui dimensi chance, factor condition, firm strategy, structure and rivalry dan government. Rata-rata skor tertinggi terdapat pada dimensi firm strategy, structure and rivalry. Hal ini menunjukkan adanya penilaian baik dari responden mengenai firm strategy, structure and rivalry membuat petani melakukan pemasaran secara online Sedangkan ratarata skor terendah terdapat pada dimensi government.

3. Gambaran pendapatan diukur melalui presentase pendapatan, volume penjualan dan laba. Gambaran pendapatan terlihat mengalami penurunan dan kenaikan.

4. Terdapat pengaruh positif digital marketing terhadap pendapatan

5. Terdapat pengaruh negatif daya saing terhadap pendapatan

\section{Daftar Pustaka}

Aisyah, A. N. 2018. Penerapan Digital Marketing Dan Pengaruhnya Terhadap Keberhasilan Usaha Mikro, Kecil Dan Menengah Sektor Kreatif Di Indonesia Dan Malaysia. Essentials of Marketing Management 298-307. https://doi.org/10.4324/9781315177014-11

Anshari, M. F., \& Mahani, S. E. 2018. Pengaruh Digital Marketing dan Sales Promotion terhadap Impulse Buying pada Situs Berrybenka . com ( Studi Kasus pada Masyarakat Kota Bandung ), 1174-1179.

Barat, B. P. S. J. 2018. Indikator Statistik Terkini, (Disember), 2-23. Retrieved from http://www.motac.gov.my/muat-turun/send/11homestay/65-statistik-homestay-sehinggadisember-2018

Febriyantoro, M. T., \& Arisandi, D. 2018. Pemanfaatan Digital Marketing Bagi Usaha Mikro, Kecil Dan Menengah Pada Era Masyarakat Ekonomi Asean. JMD: Jurnal Riset Manajemen \& Bisnis Dewantara, 1(2), 61-76. https://doi.org/10.26533/jmd.v1i2.175

Hasibuan, J. S. 2013. Analisis Kontribusi Sektor Industri Terhadap PDRB Kota Medan. Jurnal Ilmu Ekonomi Dan Studi Pembangunan, 3(1), 53-61. Retrieved from http://jurnal.umsu.ac.id/index.php/ekawan/article/vi ew/230/pdf_24

Holliman, G., \& Rowley, J. 2014. Business to business digital content marketing: Marketers' perceptions of best practice. Journal of Research in Interactive Marketing, 8(4), 269-293. https://doi.org/10.1108/JRIM-02-2014-0013

Lakutomo, G. 2014. Analisis Pemasaran Terhadap Bisnis Online (E-Commerce) Dalam Jaringan sosial Internet, 317-331. 
Liputan6.com. 2019. 10 Perbedaan Penelitian Kualitatif dan Kuantitatif, Mahasiswa Wajib Tahu - News Liputan6.com. Retrieved June 22, 2019, from https://www.liputan6.com/news/read/3867330/10perbedaan-penelitian-kualitatif-dan-kuantitatif mahasiswa-wajib-tahu.

Manek, D. 2013. Analisis Pengaruh Orientasi Pasar Terhadap Kinerja Pemasaran Pada Perusahaan Pengolahan Di Kota Semarang. Sains Pemasaran Indonesia, XII(2), 121-148.

OVILIA, A. V. 2018. Pengaruh Sektor Pertanian Dan Sektor Perdagangan Terhadap Produk Domestik Regional Bruto (Pdrb) Kabupaten Pringsewu Periode 2008-2016 Dalam Perspektif Ekonomi Islam, III, 224-234.

Pradiani, T. 2017. Pengaruh Sistem Pemasaran Digital Marketing Terhadap Peningkatan Volume Penjualan Hasil Industri Rumahan. Jurnal Ilmiah Bisnis Dan Ekonomi Asia, 11(2), 46-53. https://doi.org/10.32812/jibeka.v11i2.45

Reminta Lumban Batu. 2013. Analisis Citra Perguruan Tinggi Amerika Serikat Terhadap Keputusan Untuk Melanjutkan Studi (Survei Pada Komunitas Persatuan Mahasiswa Indonesia Di Amerika Serikat) Universitas Pendidikan Indonesia, 48-72.

Rohmanudin. 2017. Analisis Strategi Pemasaran Dalam Meningkatkan Daya Saing (Studi Pada Industri Mebel di Kecamatan Wayhalim Kota Bandar Lampung), (December).

Saveria, R. A. 2016. Analisis Digital Marketing Dalam Strategi Integrated Marketing Communication Kampanye Politik (Studi Kasus Komunitas Teman Ahok).

Siwu, H. F. D. 2018. Strategi pertumbuhan dan pembangunan ekonomi daerah, 1-11.

Sora N. 2015. Pengertian Populasi Dan Sampel Serta Teknik Sampling - Pengertian Apapun. Retrieved November 11, 2018, from http://www.pengertianku.net/2015/03/pengertianpopulasi-dan-sampel-serta-teknik-sampling.html

Susanto, A., Susilo, H., Administrasi, F. I., \& Malang, U. B. 2013. Penggunaan Web Sebagai Salah Satu Pendukung Strategi Pemasaran Produk Oleh Perusahaan Kusuma Agro Industri Batu. Jurnal Administrasi Bisnis, 5(2), 1-11.

Ulil Azmi, M. 2016. Pengaruh Program Komunikasi Pada Digital Marketing Dan Sales Promotion Terhadap Impulse Buying Pada Konsumen Situs Lazada.Co.Id. Program Studi Ilmu Komunikasi Falsafah Dan Peradaban Paramadina. Retrieved from https://ulilazmiportofolio.files.wordpress.com/2017 /09/skripsi-lazada-paramadina.pdf

Wibowo, J. B. 2018. Analisis Perbandingan antara Pendapatan Driver Go-Jek Full Time dan Upah Minimum Regional Kota Studi Kasus di Kota Yogyakarta, III, 224-234.

Wulandari, A. A. R., \& Darsana, I. B. 2017. Pengaruh Modal, Tenaga Kerja , Dan Lama Usaha Terhadap Pendapatan Pengrajin Industri. E-Jurnal Ep Unud,
6(4), 564-596

www.karawangkab.go.id. 2019. Di Usia 382 Tahun Kabupaten Karawang Semakin Memantapkan Kiprahnya Dalam Pembangunan Dengan Berbagai Prestasi | Situs Resmi - Pemerintah Daerah Kabupaten Karawang. Retrieved June 22, 2019, from https://www.karawangkab.go.id/headline/diusia-382-tahun-kabupaten-karawang-semakinmemantapkan-kiprahnya-dalam-pembangunandengan-berbagai-prestasi. 